\title{
Red meat intake-induced increases in fecal water genotoxicity correlate with pro-carcinogenic gene expression changes in the human colon.
}

Citation for published version (APA):

Hebels, D., Sveje, K. M., de Kok, M. C., van Herwijnen, M. H., Kuhnle, G. G., Engels, L. G. B., Vleugels Simon, C. B., Mares, W. G., Pierik, M. J., Masclee, A. A. M., Kleinjans, J., \& de Kok, T. M. (2012). Red meat intake-induced increases in fecal water genotoxicity correlate with pro-carcinogenic gene expression changes in the human colon. Food and Chemical Toxicology, 50(2), 95-103.

https://doi.org/10.1016/j.fct.2011.10.038

Document status and date:

Published: 01/01/2012

DOI:

10.1016/j.fct.2011.10.038

Document Version:

Publisher's PDF, also known as Version of record

Document license:

Taverne

Please check the document version of this publication:

- A submitted manuscript is the version of the article upon submission and before peer-review. There can be important differences between the submitted version and the official published version of record.

People interested in the research are advised to contact the author for the final version of the publication, or visit the DOI to the publisher's website.

- The final author version and the galley proof are versions of the publication after peer review.

- The final published version features the final layout of the paper including the volume, issue and page numbers.

Link to publication

\footnotetext{
General rights rights.

- You may freely distribute the URL identifying the publication in the public portal. please follow below link for the End User Agreement:

www.umlib.nl/taverne-license

Take down policy

If you believe that this document breaches copyright please contact us at:

repository@maastrichtuniversity.nl

providing details and we will investigate your claim.
}

Copyright and moral rights for the publications made accessible in the public portal are retained by the authors and/or other copyright owners and it is a condition of accessing publications that users recognise and abide by the legal requirements associated with these

- Users may download and print one copy of any publication from the public portal for the purpose of private study or research.

- You may not further distribute the material or use it for any profit-making activity or commercial gain

If the publication is distributed under the terms of Article $25 \mathrm{fa}$ of the Dutch Copyright Act, indicated by the "Taverne" license above, 


\title{
Red meat intake-induced increases in fecal water genotoxicity correlate with pro-carcinogenic gene expression changes in the human colon
}

\author{
Dennie G.A.J. Hebels ${ }^{a}, *$, Kirstine M. Sveje ${ }^{a}$, Marloes C. de Kok ${ }^{a}$, Marcel H.M. van Herwijnen ${ }^{a}$, \\ Gunter G.C. Kuhnle ${ }^{\text {b,1 }}$, Leopold G.J.B. Engels ${ }^{c}$, Carla B.E.M. Vleugels-Simon ${ }^{\text {c }}$, Wout G.N. Mares ${ }^{\text {c,d }}$, \\ Marieke Pierik $^{\mathrm{d}}$, Ad A.M. Masclee ${ }^{\mathrm{d}}$, Jos C.S. Kleinjans ${ }^{\mathrm{a}}$, Theo M.C.M. de Kok ${ }^{\mathrm{a}}$ \\ ${ }^{a}$ Department of Toxicogenomics, Maastricht University, P.O. Box 616, 6200 MD Maastricht, The Netherlands \\ ${ }^{\mathrm{b}}$ MRC Epidemiology Unit, Institute of Metabolic Science, Addenbrooke's Hospital, P.O. Box 285, Cambridge CB2 0QQ, United Kingdom \\ ${ }^{\mathrm{c}}$ Department of Gastroenterology, Orbis Medical Center, P.O. Box 5500, 6130 MB Sittard-Geleen, The Netherlands \\ ${ }^{\mathrm{d}}$ Department of Internal Medicine, Division of Gastroenterology and Hepatology, Maastricht University Medical Center, P.O. Box 5800, 6202 AZ Maastricht, The Netherlands
}

\section{A R T I C L E I N F O}

\section{Article history:}

Received 2 August 2011

Accepted 5 October 2011

Available online 14 October 2011

\section{Keywords:}

Colorectal cancer

Endogenous nitrosation

Fecal water genotoxicity

$N$-nitroso compounds

Nitrosamines

Whole genome gene expression

\begin{abstract}
A B S T R A C T
Red meat consumption is associated with an increased colorectal cancer (CRC) risk, which may be due to an increased endogenous formation of genotoxic $N$-nitroso compounds (NOCs). To assess the impact of red meat consumption on potential risk factors of CRC, we investigated the effect of a 7-day dietary red meat intervention in human subjects on endogenous NOC formation and fecal water genotoxicity in relation to genome-wide transcriptomic changes induced in colonic tissue. The intervention showed no effect on fecal NOC excretion but fecal water genotoxicity significantly increased in response to red meat intake. Colonic inflammation caused by inflammatory bowel disease, which has been suggested to stimulate endogenous nitrosation, did not influence fecal NOC excretion or fecal water genotoxicity. Transcriptomic analyses revealed that genes significantly correlating with the increase in fecal water genotoxicity were involved in biological pathways indicative of genotoxic effects, including modifications in DNA damage repair, cell cycle, and apoptosis pathways. Moreover, WNT signaling and nucleosome remodeling pathways were modulated which are implicated in human CRC development. We conclude that the gene expression changes identified in this study corroborate the genotoxic potential of diets high in red meat and point towards a potentially increased CRC risk in humans.
\end{abstract}

(c) 2011 Elsevier Ltd. All rights reserved.

\section{Introduction}

Consumption of red meat is associated with a higher risk of colorectal cancer (CRC) and this may be a result of an increased genotoxic stress in the colon since diets high in red meat content have been found to increase fecal water genotoxicity (Pearson et al., 2009). Aside from the formation of food preparation-related heterocyclic amines (HCAs) and polycyclic aromatic hydrocarbons (PAHs), it has also been proposed that endogenously formed $\mathrm{N}$-nitroso compounds (NOCs) are responsible for the link between red meat consumption and CRC risk (Bingham et al., 1996; Cross

Abbreviations: ATNC, apparent total nitroso compounds; CRC, colorectal cancer; FDR, false discovery rate; Fpg, formamidopyrimidine-DNA glycosylase; GEO, Gene Expression Omnibus; HCAs, heterocyclic amines; IBD, inflammatory bowel disease; IBS, irritable bowel syndrome; NOCs, $N$-nitroso compounds; PAHs, polycyclic aromatic hydrocarbons; TM, tail moment.

* Corresponding author. Tel.: +31 43 3881088; fax: +31 433884146

E-mail address: d.hebels@maastrichtuniversity.nl (D.G.A.J. Hebels).

${ }^{1}$ Present address: Department of Food and Nutritional Sciences, University of Reading, P.O. Box 226, Reading RG6 6AP, United Kingdom. and Sinha, 2004; Wakabayashi et al., 1992) since red meat is known to stimulate NOC formation in the colon (Kuhnle and Bingham, 2007). Meat in general is a source of NOC precursors in the form of amines and amides and heme protein present in red meat is thought to catalyze endogenous nitrosation (Cross et al., 2003; Haorah et al., 2001). In addition, meat products, and especially processed meat products, already contain pre-formed NOCs (Ozel et al., 2010). As most NOCs have mutagenic and genotoxic properties, which explain their carcinogenic effect in test animals (Lijinsky, 1992; Rao et al., 1984), they may also contribute to CRC development in humans. Moreover, gene expression changes associated with NOC exposure could play a part in the carcinogenic process. Indeed, following NOC exposure in vitro, transcriptomic modifications in important developmental signaling pathways have been found that may influence their carcinogenic effects (Hebels et al., 2009, 2010).

We have previously investigated the possible role of NOCs in human CRC development by studying gene expression modifications associated with exposure to these compounds in the inflamed human colon (Hebels et al., 2011). There are indications that 
inflammation stimulates endogenous nitrosation which makes the inflamed colon an interesting model to study the effect of NOCs in relation to CRC (de Kok et al., 2005; Mirvish et al., 2003). Although we were unable to detect this stimulatory effect in our previous study by comparing patients with inflammatory bowel disease (IBD) with irritable bowel syndrome (IBS) patients who served as controls, we did find transcriptomic changes in colonic tissue in relation with fecal NOC levels that may contribute to pre-carcinogenic events induced in the colon.

The relation between red meat consumption and increased levels of nitrosation makes a dietary red meat intervention study suitable as a model for investigating NOC exposure-associated gene expression changes in the human colon. Furthermore, an interaction between inflammation as a result of IBD and red meat consumption may hypothetically result in an even higher rate of fecal nitrosation. In the present study, we therefore investigated the impact of dietary red meat intake on fecal NOC formation and fecal water genotoxicity in relation to transcriptomic changes induced in colonic tissue obtained from a subset of subjects from our previous study (Hebels et al., 2011). Gene expression changes identified in this study may be helpful in explaining the role of red meat consumption in human CRC.

\section{Materials and methods}

\subsection{Subjects, study design, and food diary analysis}

The study population was recruited in the Netherlands at the Department of Gastroenterology in the Orbis Medical Center in Sittard and the Maastricht University Medical Center and consists of a subset of 12 subjects who participated in our previous study (Hebels et al., 2011). The difference between these 12 subjects and the remaining subjects in our previous study is that these 12 subjects also volunteered to participate in a dietary red meat intervention. Six of these subjects were diagnosed with IBD ( 5 male, 1 female, mean age $51.2 \pm 14.5$, range $31-71$ years) and the other six with IBS ( 3 male, 3 female, mean age 55.0 \pm 15.0 , range 25-65 years), thus allowing for a comparison of the effect of a diet high in red meat between IBD subjects and inflammation-free IBS control subjects. The IBD patients were only considered eligible when they had a history of ulcerative colitis with a moderate exacerbation of the inflammatory state at the time of inclusion as based on an anamnesis and the scheduled colonoscopy. Crohn's disease patients were excluded from participation as well as patients who had to be admitted to hospital due to severity of the disease or had a history of colorectal adenomas. An exacerbation of inflammation was characterized by increased intestinal cramps, increased incidence of fecal blood, and changes in stool consistency or frequency of bowel movements. Vomiting or severe diarrhea did not occur in the participating subjects. Only IBS patients proven free (as evaluated by colonoscopy) from colorectal disease (including inflammation) and other gastrointestinal disorders were included as controls. None of the subjects suffered from obesity.

After enrollment, food diaries were filled out on three consecutive days, after which subjects collected a first feces sample. This was immediately frozen $\left(-20^{\circ} \mathrm{C}\right)$ upon collection. During a colonoscopic examination, following the collection of the first feces sample, six biopsies were taken from mucosal tissue in visually non-inflamed regions of the colon (in most cases from the sigmoid and descending colon) which were immediately frozen in liquid nitrogen and stored at $-80{ }^{\circ} \mathrm{C}$ until use. The intervention week started immediately after the first colonoscopy exam and involved a high red meat diet consisting of $300 \mathrm{~g}$ of red meat/day for 7 days. Only beef products were consumed, which included round steak, entrecôte, veal schnitzel, veal cutlet, and veal escalope. Participants were instructed to pan-fry the meat medium, regularly flip it, and avoid charring, as to minimize HCA and $\mathrm{PAH}$ formation, and were not allowed to eat any other meats (including meat toppings, fish and other seafood) during the intervention week. Food diaries were filled out daily during this week. Three days before and during the intervention period subjects followed their normal dietary habits, with a few modifications. To keep nitrate intake between subjects similar, participants were asked to use low-nitrate mineral water when preparing food or drinks and to avoid vegetables with high nitrate concentrations, such as spinach, lettuce, and celery. A high fruit consumption, especially fruit rich in vitamin C, and use of vitamin supplements also had to be avoided as this has been reported to inhibit endogenous nitrosation (Vermeer et al., 1999).

After the intervention, a second colonoscopy was performed and six biopsies were taken at the same location as in the first exam. Subjects collected a second feces sample on the last intervention day prior to the colonoscopy which was also immediately frozen $\left(-20^{\circ} \mathrm{C}\right)$ upon collection. The first colonoscopy was performed as part of either surveillance or suspected gastrointestinal disorders, while the second colonoscopy was performed solely for the purpose of this study. Standard med- ication of all IBD patients during participation consisted of the immunosuppressor 5 -aminosalicylic acid. Use of additional anti-inflammatory medication in IBD patients to treat the exacerbated colon inflammation was postponed until the end of the study.

Subjects were instructed to record their daily dietary intake during the study using standardized food diaries. Daily diaries consisted of a list of several dozens of frequently consumed food items and additional room to write down items not on the list. For each food item, the amount consumed (standard portions: number of units, glasses, cups) was recorded, as well as the cooking method if applicable (e.g. frying, boiling, etc.). Food diaries were processed to calculate the average daily amounts of energy and nutrients using the software program "Eetmeter" designed by the Netherlands Nutrition Center (Netherlands Nutrition Centre [Stichting Voedingscentrum Nederland], 2010).

This study was approved by the Medical Ethical Committees Atrium Orbis Zuyd and Clinical Trial Center Maastricht (Registration number: NL13359.096.06) and written informed consent was obtained from the participants prior to the start of the study.

\subsection{Fecal apparent total $N$-nitroso compound determination}

Apparent total $N$-nitroso compounds (ATNC), as a measure for NOCs, were analyzed in feces as described previously (Kuhnle et al., 2007), using an Ecomedics CLD 88 Exhalyzer (Ecomedics, Duernten, Switzerland). In short, $100 \mathrm{mg}$ fecal material was diluted 1:5 in ultrapure water and homogenized for $20 \mathrm{~min}$. Thereafter, $500 \mu \mathrm{l}$ of a $5 \%(\mathrm{wt} / \mathrm{vol}$ ) sulfamic acid solution was added to remove nitrite and samples were injected into a purge vessel kept at $60^{\circ} \mathrm{C}$ and filled with a standard triiodide reagent ( $38 \mathrm{mg} \mathrm{I}_{2}$ was added to a solution of $108 \mathrm{mg} \mathrm{KI}$ in $1 \mathrm{ml}$ water; to this mixture, $13.5 \mathrm{ml}$ glacial acetic acid was added) to determine ATNC. Results are presented as nmol ATNC/g feces.

\subsection{Fecal water alkaline single-cell gel electrophoresis (comet assay)}

Fecal water samples were prepared from fecal material collected from patients who participated in the red meat intervention. After manual homogenization of the fecal material for $2 \mathrm{~min}$, samples were ultracentrifuged at $50,000 \mathrm{~g}$ for $2 \mathrm{~h}$ at $10^{\circ} \mathrm{C}$. The supernatant fecal water was aliquoted and stored at $-20^{\circ} \mathrm{C}$ until use. The human colon adenocarcinoma cell line Caco-2 was used to test fecal water genotoxicity in the standard and formamidopyrimidine-DNA glycosylase (Fpg) comet assay. Fpg cuts the DNA strand specifically at oxidized purines and thus creates more strand breaks which represent oxidative DNA damage. Caco-2 cells were cultured in DMEM (Sigma-Aldrich, Zwijndrecht, The Netherlands) supplemented with $1 \%$ (v/v) nonessential amino acids, $1 \%$ Na-pyruvate, $1 \%$ penicillin/streptomycin, and $10 \%(\mathrm{v} / \mathrm{v})$ heat-inactivated fetal calf serum, all purchased from Gibco BRL (Breda, The Netherlands). Cell cultures were incubated at $37^{\circ} \mathrm{C}$ in a humidified incubator containing $5 \% \mathrm{CO}_{2}$. For fecal water exposures, cells were harvested by trypsinization and resuspended in growth medium containing $10 \%$ fecal water followed by a $30 \mathrm{~min}$ incubation at $37^{\circ} \mathrm{C}$. After incubation, cells were centrifuged ( $300 \mathrm{~g}, 5 \mathrm{~min}$ ), washed once in phosphate buffered saline, and placed on ice. The standard and Fpg alkaline comet assays were subsequently performed in triplicate as described by Singh et al. (1988) and Pflaum et al. (1997) with minor modifications. Comets were visualized using a Zeiss Axioskop fluorescence microscope (at $200 \times$ magnification). Randomly, 50 cells were analyzed using the Comet assay III software (Perceptive Instruments, Haverhill, UK). DNA damage was expressed as tail moment (TM, the product of tail DNA content and mean tail migration distance). In each experiment, control cells from a batch of frozen $\mathrm{H}_{2} \mathrm{O}_{2}$ exposed Caco-2 cells $\left(100 \mu \mathrm{M}, 30 \mathrm{~min}\right.$, frozen at $-80{ }^{\circ} \mathrm{C}$ in freeze medium containing $10 \%$ DMSO) were co-electrophorized and scored along with the fecal water-exposed cells to compensate for any inter-electrophoresis variation.

\subsection{Microarray hybridization and data analysis}

From each subject, three biopsies were separately dissolved in QIAzol ${ }^{\circledR}$ (Qiagen, Venlo, The Netherlands) using a tissue disruptor, and subsequently pooled. RNA was isolated according to the manufacturer's protocol (average RNA integrity number: $7.1 \pm 1.0)$. Microarray hybridization was performed as described previously with some modifications (Hebels et al., 2009). In short, dye-labeled cRNA (Cy3) was synthesized following the one-color labeling protocol supplied by the manufacturer (Agilent Technologies, Amstelveen, The Netherlands). Dye incorporation rates were used to hybridize equal amounts of Cy3-labeled samples (i.e. 20 pmol Cy3) to Agilent $4 \mathrm{x} 44 \mathrm{~K}$ Whole Human Genome microarrays. Slides were subsequently washed and dried. After scanning the microarray slides (wavelength $532 \mathrm{~nm}$, laser power $100 \%$, photo multiplier tube gain saturation tolerance $0.02 \%$ ), bad and empty spots were flagged using the GenePix Pro software (version 6.0, Molecular Devices, Sunnyvale, CA). Quality control was performed in the statistical software environment R (version 2.10.1, The R Foundation for Statistical Computing, Vienna, Austria). Quantile normalization and subsequent data processing was performed in ArrayTrack (version 3.4, NCTR, Jefferson, AR). Log2 transformed spot intensities were used for further analyses. 
ArrayTrack and Microsoft Excel were used to find genes significantly modulated as a result of the red meat intervention groups by combining a log ratio (after/before) ranking (absolute $\log 2$ ratio $>0.5$ ) with a non-stringent $p$-value cut-off (paired $t$-test, $p<0.05$ ), as suggested by Shi et al. (2006). The Benjamini-Hochberg false discovery rate (FDR) at this $p$-value was $<15 \%$. Further filtering was performed by selecting only gene pairs (before paired with after) that were present in at least eight out of 12 subjects. Genes were subsequently imported in MetaCore ${ }^{\mathrm{TM}}$ (GeneGo, San Diego, CA) to identify the involvement of differentially expressed genes in specific cellular GeneGO pathways. Pathways with a $p<0.05$ were considered significantly modulated.

For Spearman's rank correlation analyses, gene expression data from all 12 subjects were correlated with genotoxicity levels (TMs from standard and Fpg come assays). Only genes present in at least $70 \%$ of subjects were used without further pre-selection. Prior to correlation analysis, missing values were imputed in GenePattern (version 3.1, http://www.broad.mit.edu/cancer/software/genepattern/) by finding the $k$ nearest neighbors ( $k$ was set to 15 ), using a Euclidean metric, and imputing the missing elements by averaging the (non-missing) elements of its neighbors. The online Gene Expression Profile Analysis Suite (version 4.0, http:// gepas.bioinfo.cipf.es/) was used to perform correlation analyses and significantly correlating genes $(p<0.05)$ with a minimum correlation coefficient of 0.4 were subsequently further analyzed in MetaCore. The Benjamini-Hochberg FDR at this $p$-value was $<6 \%$.

For all pathways identified in MetaCore the Benjamini-Hochberg FDR was also calculated and the associated $q$-values are reported.

The gene expression data discussed in this publication have been deposited in NCBI's (National Center for Biotechnology Information) Gene Expression Omnibus (GEO) and are available through GEO Series accession number GSE25220 (http:// www.ncbi.nlm.nih.gov/geo/query/acc.cgi?acc=GSE25220).

\subsection{Statistical analysis of non-microarray data}

Results are presented as mean \pm SD. Normality of data sets was tested using the Kolmogorov-Smirnov test. Potential differences between groups were assessed using the Student's $t$-test (for equal or unequal variances, as based on Levene's test), paired $t$-test or Wilcoxon signed-rank test depending on the normality of data and presence of paired samples.

\section{Results}

\subsection{Dietary intake during red meat intervention}

The results of the food diary analysis of nutrients and food groups are presented in Table 1 and are consistent with the significantly increased intake of red meat $(p<0.0001)$. The average daily dietary intake of protein, animal protein, potassium, and zinc was significantly increased during the red meat intervention as compared to before $(p<0.05$ or $<0.01)$. White meat intake was significantly decreased during the intervention as a result of the dietary restrictions $(p<0.05)$. All other dietary components or food groups were not significantly influenced by the intervention.

\subsection{Fecal ATNC levels}

Fecal material of subjects completing the red meat intervention was first analyzed for ATNC content. IBD patient and IBS control groups were initially analyzed separately for covering the possibility of detecting an additional effect of inflammation on endogenous nitrosation during the intervention period. However, neither the IBS nor the IBD patients displayed a significant difference in fecal ATNC levels after the intervention (paired $t$-test) and there were no differences between IBS and IBD patients before or after the red meat intervention period (Student's $t$-test) (Fig. 1), nor was there a significant correlation with calprotectin levels, a marker for inflammation severity, measured in our previous study (results not shown) (Hebels et al., 2011). One IBS subject displayed a strong increase in fecal ATNC content, but this could not be linked to an unusual increase or decrease of a nutrient or food group as compared to the other subjects. Combining all subjects also showed no significant effect of the intervention on fecal ATNC levels and there was no significant correlation with the reported red meat intake (results not shown).

\subsection{Fecal water genotoxicity}

Although endogenous NOC formation was not significantly affected by the red meat diet, we investigated in vitro fecal water genotoxicity of all subjects before and after the red meat intervention as a broader marker of exposure and which is known to respond to increased red meat intake. Fecal water genotoxicity reflects the balance between all genotoxic fecal water constituents that induce DNA damage and those with potential protective properties. Individual fecal water genotoxicity levels are presented in Fig. 2. In 10 out of 12 subjects fecal water genotoxicity appeared to be increased after the meat intervention, while the remaining two subjects did not respond to meat intake. Similar to fecal ATNC levels, there was no significant difference in genotoxicity level between IBD patients and IBS controls before or after the intervention (Student's $t$-test) and genotoxicity also did not significantly correlate with calprotectin levels measured in our previous study (results not shown) (Hebels et al., 2011). Therefore both groups were combined to determine the effect of the red meat intervention (Table 2). Since inter-individual variability in fecal water genotoxicity was high, the Wilcoxon signed-rank test was used. Averaged at group level, the intervention resulted in a significant increase in genotoxicity of more than a factor 2 in both the standard and the Fpg comet assay $(p<0.05)$. Incubation with Fpg enzyme led to a significant increase in DNA strand breaks compared to the standard comet assay both before and after the intervention ( $p<0.01$ ), indicating the presence of oxidized purines. As can be expected from the absence of an increase in fecal ATNC after the intervention, genotoxicity levels did not significantly correlate with fecal ATNC levels.

\subsection{Gene expression modifications associated with red meat intervention}

Since fecal ATNC and genotoxicity levels were not different between IBS and IBD subjects, for subsequent transcriptomic analyses both groups were combined to find red meat interventionrelated gene expression modifications. To analyze whether the intervention influenced the expression of genes in these subjects, modulated genes were identified as having an absolute $\log 2$ ratio $>0.5$ and a paired $t$-test $p<0.05$. The complete list of modulated genes is presented in Suppl. Table 1. At this $p$-value the FDR was below $15 \%$. As shown by the heatmap in Suppl. Fig. 1, all significantly modulated genes show a similar behavior (i.e. up or down regulation) for the majority of subjects. Significantly modulated genes were subsequently analyzed in MetaCore. A small number of GeneGO pathways were found to be significantly modified by meat consumption (Table 3). Pathways were involved in several processes, including cytoskeleton remodeling, development, and immune response, but the percentages of involved genes for each pathway are low, indicating only small effects. An overview of the significantly modulated genes in each pathway and the pathway maps are presented in Suppl. Table 2 and Suppl. Figs. 2A-I, respectively. The pathway maps contain directional indicators (up or down regulation) for every significantly modulated gene in the pathway to allow for an assessment of the net biological effect on the pathway.

\subsection{Fecal water genotoxicity-associated gene expression modifications}

By specifically looking at gene expression changes associated with the overall increase in fecal water genotoxicity as a phenotypic marker of effect, relevant genes may be identified that are otherwise missed when comparing the before and after measurements with each other. To investigate the transcriptomic response linked to the increase in fecal water genotoxicity we performed a 
Table 1

Reported average daily dietary intake before and during the red meat intervention for all subjects $(n=12)$.

\begin{tabular}{|c|c|c|c|c|}
\hline \multirow[t]{2}{*}{ Dietary intake (average/day) } & \multicolumn{2}{|c|}{ Before intervention } & \multicolumn{2}{|c|}{ During intervention } \\
\hline & Mean \pm SD & Median [range] & Mean \pm SD & Median [range] \\
\hline Energy (kcal) & $2072 \pm 596$ & 2147 [1215.3-3095] & $2028 \pm 509$ & 1919 [1268.9-2964.3] \\
\hline Protein $(\mathrm{g})$ & $80.0 \pm 24.7$ & $81[42-120.7]$ & $121 \pm 19.2^{\mathrm{b}}$ & $117[98-161.3]$ \\
\hline Animal protein $(\mathrm{g})$ & $32.0 \pm 24.9$ & $23.8[8-90]$ & $69.6 \pm 11.2^{\mathrm{b}}$ & $72.3[41.4-80.1]$ \\
\hline Total fat $(\mathrm{g})$ & $85.7 \pm 37.8$ & $86.7[32.7-145.3]$ & $73.8 \pm 23.6$ & 67 [39.6-115.9] \\
\hline Saturated fat (g) & $29.9 \pm 12.3$ & $30.4[10.7-51]$ & $29.7 \pm 8.2$ & 29 [16.7-39.4] \\
\hline Cholesterol (mg) & $226 \pm 144$ & $174[103.3-525.7]$ & $274 \pm 101$ & 265 [135-481.7] \\
\hline Carbohydrates (g) & $199 \pm 57.3$ & $200[123-283.3]$ & $196 \pm 70.5$ & 208 [84.9-291.9] \\
\hline Fibers (g) & $19.2 \pm 6.2$ & $17.4[13-31.3]$ & $19.9 \pm 7.2$ & $19.2[10.1-30.4]$ \\
\hline Alcohol (g) & $19.4 \pm 15.5$ & $11.9[0-48]$ & $14.5 \pm 13.4$ & $12.4[0-43.7]$ \\
\hline Water $(\mathrm{g})$ & $1579 \pm 358$ & 1551 [1065.3-2037] & $1671 \pm 467$ & $1768[1008.6-2306.6]$ \\
\hline Sodium (mg) & $3305 \pm 928$ & 3032 [1897.7-4736.7] & $2991 \pm 751$ & 2977 [2004.9-4445.3] \\
\hline Potassium (mg) & $2702 \pm 596$ & 2799 [1781.3-3690.7] & $3408 \pm 771^{\mathrm{c}}$ & 3456 [2395.9-4669.6] \\
\hline Calcium (mg) & $632 \pm 241$ & 650 [299.7-896] & $762 \pm 283$ & 718 [428.7-1246.9] \\
\hline Magnesium (mg) & $281 \pm 68.8$ & 271 [177.3-398] & $303 \pm 90.7$ & $295[191.3-442.1]$ \\
\hline Iron $(\mathrm{mg})$ & $11.3 \pm 3.6$ & $11.1[6.5-17.9]$ & $12.9 \pm 4.0$ & $12.1[8.2-19.9]$ \\
\hline Selenium $(\mu \mathrm{g})$ & $52.2 \pm 42.3$ & 35.2 [18.3-159.3] & $47.3 \pm 15.6$ & 48.5 [21.7-73.3] \\
\hline Zinc $(\mathrm{mg})$ & $8.6 \pm 2.2$ & $8.8[5-11.6]$ & $13.7 \pm 2.5^{\mathrm{b}}$ & $13.3[9.2-17.2]$ \\
\hline Folic acid $(\mu \mathrm{g})$ & $142 \pm 31.4$ & 149 [90-190.7] & $152 \pm 35.4$ & 156 [103-207.1] \\
\hline Vitamin A $(\mu \mathrm{g})$ & $881 \pm 320$ & 817 [418.7-1565.7] & $694 \pm 194$ & 668 [383.4-1065.6] \\
\hline Vitamin B1 (mg) & $1.1 \pm 0.3$ & $1.15[0.6-1.4]$ & $1.4 \pm 0.5$ & $1.45[0.6-1.9]$ \\
\hline Vitamin B2 (mg) & $1.1 \pm 0.4$ & $0.95[0.5-1.7]$ & $1.1 \pm 0.4$ & $1.05[0.6-1.9]$ \\
\hline Vitamin B3 (mg) & $18.5 \pm 7.7$ & $17.35[9-31]$ & $23.2 \pm 6.2$ & 24.95 [11.9-29.6] \\
\hline Vitamin B6 (mg) & $1.6 \pm 0.5$ & $1.65[0.9-2.6]$ & $1.7 \pm 0.4$ & $1.6[1.2-2.3]$ \\
\hline Vitamin B12 $(\mu \mathrm{g})$ & $4.3 \pm 4.0$ & $2.95[0.6-13.6]$ & $5.6 \pm 1.9$ & $4.9[3.8-9.3]$ \\
\hline Vitamin C (mg) & $34.7 \pm 15.8$ & $29.5[22-73.7]$ & $49.5 \pm 16.6$ & $47[27.4-74.4]$ \\
\hline Vitamin D $(\mu \mathrm{g})$ & $5.9 \pm 4.4$ & $4.8[1.2-16.4]$ & $4.0 \pm 1.3$ & $4.6[2.2-5.8]$ \\
\hline Vitamin E (mg) & $15.9 \pm 11.4$ & $13.7[3.1-36.7]$ & $13.3 \pm 9.3$ & $11.3[3.2-30.7]$ \\
\hline \multicolumn{5}{|l|}{ Food groups } \\
\hline Red meat (g) & $88.6 \pm 53.4$ & 70 [25-186.67] & $298 \pm 42.0^{\mathrm{a}}$ & 303 [195.71-361.43] \\
\hline White meat/fish (g) & $85.6 \pm 109$ & $44.2[0-350]$ & $5.3 \pm 8.3^{\mathrm{d}}$ & $0[0-25]$ \\
\hline Fruit and vegetables (g) & $144 \pm 96.1$ & $143[0-307.5]$ & $160 \pm 81.3$ & 147 [21.43-294.29] \\
\hline Dairy products $(\mathrm{g})$ & $137 \pm 108$ & $123[36-412]$ & $198 \pm 159$ & $113[61-550.86]$ \\
\hline Bread and cereals (g) & $326 \pm 84.5$ & 339 [176.67-463.67] & $333 \pm 87.7$ & $350[147.86-435.71]$ \\
\hline
\end{tabular}

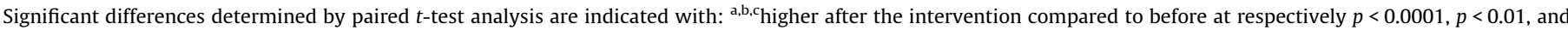
$p<0.05$; ${ }^{d}$ lower after the intervention compared to before at $p<0.05$.

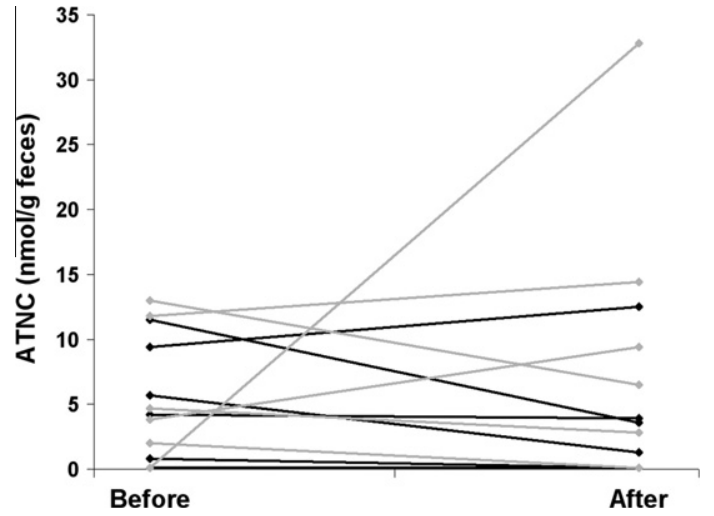

Fig. 1. Fecal apparent total $N$-nitroso compounds (ATNC) levels in IBD (black lines) and IBS patients (gray lines) before and after the red meat intervention. No significant differences were detected between before and after measurements or between IBS and IBD subjects.

Spearman's rank correlation analysis between TM levels and log2 gene expression intensities. Two separate correlation analyses were performed, using TMs from the standard and the Fpg comet assay. The complete list of significantly correlating genes $(p<0.05)$ is presented in Suppl. Table 3. At this $p$-value the FDR was below $6 \%$. Significantly correlating genes with a minimum correlation coefficient of 0.4 from both analyses were subsequently analyzed in MetaCore for their involvement in GeneGO pathways and the two lists of pathways resulting from this analysis were combined, the results of which are presented in Table 4. An overview of the significantly correlating genes in each pathway and the pathway maps are presented in Suppl. Table 4 and Suppl. Figs. 3A-S, respectively. The pathway maps contain directional indicators (positive or negative correlation) for every significantly correlated gene in the pathway to allow for an assessment of the net biological effect on the pathway. Pathways were found to be involved in a wide range of cellular processes. Pathways controlling apoptosis and survival, cell cycle regulation, and DNA damage repair were significantly associated with levels of fecal genotoxicity. Pathways involved in closely related processes like cytoskeleton remodeling, cell adhesion, and proteolysis were also found. Development pathways associated with genotoxicity levels included the strongest affected pathway in the list, the WNT signaling pathway of which more than $50 \%$ of genes were correlated with genotoxicity levels and which had the lowest FDR. The other development pathways were involved in signaling pathways linked with cytoskeleton reorganization. Another strongly associated process was regulation of lipid metabolism, which contains pathways implicated in cholesterol biosynthesis.

\section{Discussion}

The underlying mechanism of the correlation between red meat consumption and cancer of the colon and rectum has been investigated for many years and endogenous formation of NOCs has been suggested to play a role in this association. Although red meat intake-induced increases in fecal NOC levels, as measured by ATNC, have been demonstrated in several studies (Bingham et al., 2002; Hughes et al., 2001; Kuhnle et al., 2007), we were unable to find 


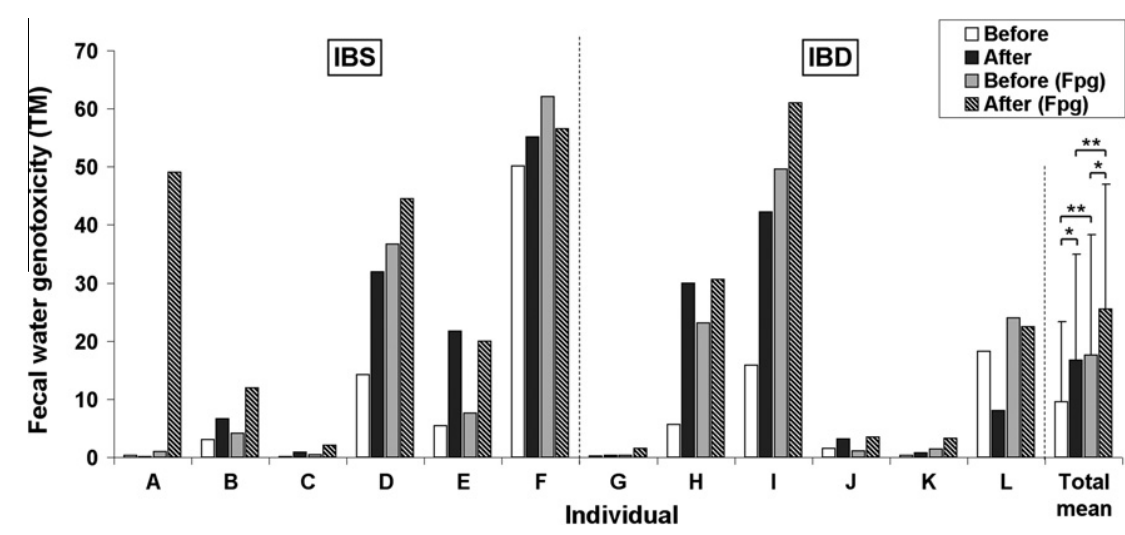

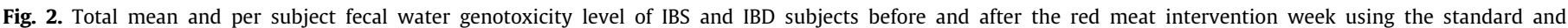

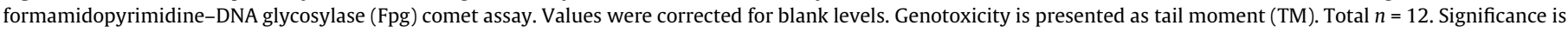
indicated by ${ }^{*}(p<0.05)$ and ${ }^{* *}(p<0.01)$.

Table 2

Fecal water genotoxicity level of all subjects before and after the red meat intervention week $(n=12)$ using the standard and Fpg comet assay.

\begin{tabular}{|c|c|c|c|c|}
\hline & \multicolumn{2}{|c|}{ Standard comet assay genotoxicity ${ }^{\mathrm{a}}$} & \multicolumn{2}{|c|}{ Fpg comet assay genotoxicity ${ }^{a}$} \\
\hline & Mean \pm SD & Median [range] & Mean \pm SD & Median [range] \\
\hline Before intervention & $9.6 \pm 13.8$ & $5.5[0.2-50.1]$ & $17.6 \pm 20.7^{\mathrm{b}}$ & $12.6[0.3-62.1]$ \\
\hline After intervention & $16.7 \pm 18.2^{\mathrm{c}}$ & $12.4[0.1-55.2]$ & $25.5 \pm 21.4^{\mathrm{b}, \mathrm{c}}$ & $21.9[1.5-61.0]$ \\
\hline Ratio after/before & $2.6 \pm 1.6$ & $2.2[0.44-5.63]$ & $2.4 \pm 1.4^{\mathrm{d}}$ & $2.5[0.91-4.88]$ \\
\hline
\end{tabular}

Measurements were corrected for blank levels.

a Genotoxicity is quantified as the average tail moment (TM) of the 12 subjects.

b TM significantly higher with Fpg $(p<0.01)$ based on Wilcoxon signed-rank test.

c TM significantly higher after the intervention $(p<0.05)$ based on Wilcoxon signed-rank test.

d Mean ratio minus outlier subject $A$.

Table 3

GeneGO pathways significantly modulated in subjects following a 7-day red meat intervention $(n=12)$.

\begin{tabular}{|c|c|c|c|}
\hline Cellular process & Pathways involved & $\%$ genes $^{\mathrm{a}}$ & $p$-value \\
\hline Atherosclerosis & Role of ZNF202 in regulation of expression of genes involved in Atherosclerosis & 25 & $0.020^{\mathrm{d}}$ \\
\hline Cytoskeleton remodeling & Fibronectin-binding integrins in cell motility & 17 & $0.042^{\mathrm{d}}$ \\
\hline \multirow[t]{3}{*}{ Development } & Notch-induced EMT & 29 & $0.000^{\mathrm{b}}$ \\
\hline & Notch signaling pathway & 13 & $0.002^{\mathrm{C}}$ \\
\hline & NOTCH1-mediated pathway for NF-KB activity modulation & 12 & $0.010^{\mathrm{d}}$ \\
\hline \multirow[t]{2}{*}{ Immune response } & CD16 signaling in NK cells & 19 & $0.030^{\mathrm{d}}$ \\
\hline & Murine NKG2D signaling & 18 & $0.038^{\mathrm{d}}$ \\
\hline Transcription & Assembly of RNA Polymerase II pre-initiation complex on TATA-less promoters & 14 & $0.026^{\mathrm{d}}$ \\
\hline Transport & Intracellular cholesterol transport & 13 & $0.036^{\mathrm{d}}$ \\
\hline
\end{tabular}

More details on the significantly modulated genes in each pathway and the pathway map images can be found in the Supplementary data Excel file.

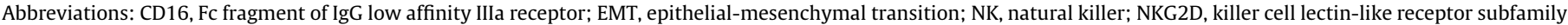

K member 1; NOTCH, Notch homolog translocation-associated (Drosophila); ZNF202, zinc finger protein 202.

a Percentage of significantly correlated genes compared to the total number of genes in the pathway.

b $q$-value $\leqslant 0.02$.

c $q$-value $\leqslant 0.18$

d $q$-value $\leqslant 0.49$.

an increase following a red meat intervention in this study (Fig. 1). The presence of inflammation in the colon, which was previously found to stimulate endogenous nitrosation (de Kok et al., 2005), in combination with the red meat diet also did not increase ATNC formation in a subgroup of subjects with IBD. Although participating IBD subjects displayed an exacerbation of their inflammatory status, the severity was generally moderate and did not cause vomiting or heavy diarrhea. In fact, severity may not have been sufficient to cause increased nitrosation (Hebels et al., 2011). As shown by the food diary analysis (Table 1 ), red meat intake, animal protein and total protein were significantly increased after the intervention, as was potassium and zinc intake, which can all be ascribed to the increase in meat consumption (Netherlands
Nutrition Centre [Stichting Voedingscentrum Nederland], 2010). The significant decrease in white meat consumption is a result of the dietary restrictions and cannot explain the absence of an increase in nitrosation. However, in contrast to other red meat diet intervention studies, food intake was not controlled in this study apart from white meat, nitrate/nitrite, and anti-oxidant vitamin restricting modifications (Bingham et al., 2002; Cross et al., 2006; Hughes et al., 2001). In addition, although the switch from their normal everyday diets to a high red meat diet did constitute a significant increase in the subjects' meat intake, this may not have been sufficient. Although a previous study found significant increases in endogenous nitrosation following a diet with only $240 \mathrm{~g}$ of red meat per day, the duration of that diet was 10 days 
Table 4

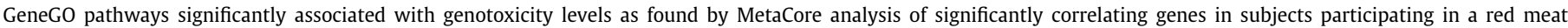
intervention $(n=12)$.

\begin{tabular}{|c|c|c|c|}
\hline Cellular process & Pathways involved & $\%$ genes $^{\mathrm{a}}$ & $p$-value \\
\hline Apoptosis and survival & Regulation of apoptosis by mitochondrial proteins & 21 & $0.017^{\mathrm{c}}$ \\
\hline \multirow[t]{2}{*}{ Carbohydrate metabolism } & Pentose phosphate pathway & 50 & $0.001^{\mathrm{b}}$ \\
\hline & Glycolysis and gluconeogenesis & 33 & $0.019^{\mathrm{d}}$ \\
\hline \multirow[t]{3}{*}{ Cell adhesion } & Integrin-mediated cell adhesion and migration & 33 & $0.018^{\mathrm{c}}$ \\
\hline & Histamine $\mathrm{H} 1$ receptor signaling in the interruption of cell barrier integrity & 24 & $0.018^{\mathrm{c}}$ \\
\hline & Role of tetraspanins in the integrin-mediated cell adhesion & 23 & $0.022^{\mathrm{d}}$ \\
\hline Cell cycle & The metaphase checkpoint & 20 & $0.015^{\mathrm{c}}$ \\
\hline \multirow[t]{2}{*}{ Cytoskeleton remodeling } & Role of PKA in cytoskeleton reorganisation & 39 & $0.007^{\mathrm{c}}$ \\
\hline & Fibronectin-binding integrins in cell motility & 29 & $0.007^{\mathrm{c}}$ \\
\hline \multirow[t]{3}{*}{ Development } & WNT signaling pathway. Part 1 . Degradation of beta-catenin in the absence of WNT signaling & 54 & $0.001^{\mathrm{b}}$ \\
\hline & Growth hormone signaling via STATs and PLC/IP3 & 22 & $0.014^{\mathrm{c}}$ \\
\hline & Slit-Robo signaling & 30 & $0.027^{\mathrm{d}}$ \\
\hline DNA damage & Role of SUMO in p53 regulation & 47 & $0.002^{\mathrm{b}}$ \\
\hline Neurophysiological process & Thyroliberin in cell hyperpolarization and excitability & 33 & $0.035^{\mathrm{d}}$ \\
\hline \multirow[t]{2}{*}{ Proteolysis } & Putative SUMO-1 pathway & 38 & $0.003^{\mathrm{b}}$ \\
\hline & Putative ubiquitin pathway & 27 & $0.023^{\mathrm{d}}$ \\
\hline \multirow[t]{2}{*}{ Regulation of lipid metabolism } & Cholesterol Biosynthesis & 40 & $0.003^{\mathrm{b}}$ \\
\hline & Niacin-HDL metabolism & 43 & $0.012^{\mathrm{C}}$ \\
\hline Transcription & Sin3 and NuRD in transcription regulation & 31 & $0.003^{\mathrm{b}}$ \\
\hline
\end{tabular}

More details on the significantly correlating genes in each pathway and the pathway map images can be found in the Supplementary data Excel file.

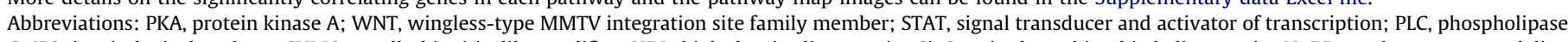

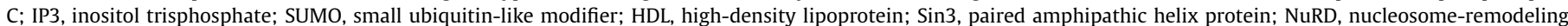
and histone deacetylation.

a Percentage of significantly correlated genes compared to the total number of genes in the pathway.

${ }^{b} q$-value $\leqslant 0.22$.

c $q$-value $\leqslant 0.59$.

d $q$-value $\leqslant 0.71$.

and it was compared to a control diet with 0 or $60 \mathrm{~g}$ of red meat per day (Hughes et al., 2001), whereas the average pre-intervention intake of red meat in this study was somewhat higher $(86 \mathrm{~g})$ and more variable. Although the number of subjects in our study was limited, previous red meat diet intervention studies used similar numbers and found significant differences (Bingham et al., 2002; Cross et al., 2006; Hughes et al., 2001). Although we did not find any significant differences between IBD and IBS subjects with regard to ATNC formation, it is still possible that the disease status introduces heterogeneity in the combined analysis that requires a larger study population. The age range of subjects in this study was comparable to other studies (Bingham et al., 2002), but differences in gender may have influenced endogenous nitrosation since previous red meat intervention studies have focused exclusively on male subjects. These factors could have introduced more variation, making it difficult to establish effects of the red meat intervention on ATNC levels.

Despite the absence of an increase in NOC formation after the red meat intervention, fecal water genotoxicity was significantly higher after the intervention (Fig. 2 and Table 2). Red meat consumption is not only associated with a more than twofold increase in fecal water genotoxicity, but oxidative stress also appears to be of relevance since both before and after the intervention, implementation of Fpg in the comet assay demonstrated significantly increased oxidative DNA damage levels. Although NOCs are capable of generating oxidative stress (Hebels et al., 2010), it is very unlikely that fecal water NOC concentrations are capable of inducing damage at levels observed in previous in vitro experiments where NOC-induced genotoxicity in Caco-2 cells was observed at millimolar concentrations which do not occur in vivo (Hebels et al., 2009). It has indeed been shown before that fecal water genotoxicity is independent of endogenous NOC formation (Cross et al., 2006), and therefore DNA damage induced as a result of an increased meat intake does not appear to be related to the presence of NOCs. Although HCAs and PAHs, which are formed during the cooking of meat, also pose a genotoxic and carcinogenic risk (Bjeldanes et al., 1982; Cross et al., 2010; Felton et al., 1994;
Jägerstad and Skog, 2005; Salmon et al., 2006), they are not likely to cause the increase in fecal genotoxicity levels as seen here either. Participants were given meat cooking instructions that are known to minimize PAH and reduce HCA formation (Jägerstad and Skog, 2005; Knize and Felton, 2005) and cooking methods did not differ from the pre-intervention period. Moreover, fecal HCA and PAH concentrations are not expected to be high enough to induce the level of DNA damage found in the comet assay as demonstrated by the low level of HCA and PAH-induced DNA adducts in human colon tissue (Autrup et al., 1978; Moonen et al., 2005). A small contribution of HCAs to the observed genotoxicity levels can, however, not be ruled out completely. Heme protein on the other hand, which is present in red meat in high levels and associated with an increased CRC risk (Balder et al., 2006; Cross et al., 2010; Lee et al., 2004; Sesink et al., 1999), has been shown to induce genotoxicity as measured by comet assay at concentrations found in the gut lumen (Glei et al., 2006). Apart from the reported heme-stimulated NOC formation (Cross et al., 2003), which was not observed in our study, heme may act as a catalyst of oxidative stress, which may also explain the increase in oxidative DNA damage in the Fpg comet assay. Heme-catalyzed oxidations can damage lipids, proteins, and DNA and a major pathway involves lipid peroxidation resulting in the formation of lipid alkoxy radicals and heme oxyradicals which can initiate further oxidations (Glei et al., 2006; Tappel, 2007).

Fecal water genotoxicity has previously been related to colon carcinogenesis in animals (Klinder et al., 2004), and the results found here support such a relation in humans as well. Red meat intake-stimulated fecal water genotoxicity may result in a higher level of DNA damage in human colonic epithelium and induce the carcinogenic process. To study the effects of the red meat intervention in more detail with emphasis on possible pro-carcinogenic modifications, we subsequently addressed differences in the transcriptomic response as a result of the intervention, with a particular focus on fecal water genotoxicity. Genes differentially regulated as a result of the red meat intervention were first investigated and found to be involved in a small number of pathways, but the 
percentage of involved genes was relatively low (Table 3). Although the three Notch signaling pathways are interesting in light of their role in gut development and homeostasis in relation to the proliferative potential of intestinal adenomas and adenocarcinomas (Bolos et al., 2007), modifications in these pathways are too limited to accurately assess their biological relevance regarding red meat intake and CRC risk. Effects on the other identified pathways suffer from the same limitation (see also Suppl. Table 2 and Suppl. Figs. 2A-I) and display a relatively large FDR, which prompted us to analyze genes specifically associated with fecal water genotoxicity since this is more directly related with a potential CRC risk. Significantly correlating genes found in this analysis not only were involved in a much larger number of pathways, the percentage of involved genes per pathway was also considerably higher (Table 4). Several of the identified pathways can be related to an increased genotoxic stress. The DNA damage pathway involved in p53 regulation, for example, would theoretically lead to breakdown of the p53 protein since the MDM2 and ubiquitin genes were both positively correlated with fecal water genotoxicity in this pathway (Suppl. Table 4 and Suppl. Fig. 3M). MDM2 and ubiquitin work together in targeting p53 for degradation (Lakin and Jackson, 1999) and this is an indication that, as a result of increased DNA damage, high levels of p53 protein are present. The two proteolysis pathways involving ubiquitin and SUMO-1 serve as an additional indicator that levels of p53 are being regulated since both are intimately involved in modifying p53 stability (see also Suppl. Figs. 30 and P) (Watson and Irwin, 2006). Because of p53's central role in the regulation of apoptosis and cell cycle progression (Levine, 1997), it is not surprising that pathways controlling these processes were also found. The identified cell cycle pathway is involved in the metaphase checkpoint while the modulated genes in the apoptosis pathway suggest an inhibition of the apoptotic process, since several pro-apoptotic genes were lowered in expression (Suppl. Table 4 and Suppl. Figs. 3A and G). This is an indication that after the intervention the balance between growth arrest (to repair DNA damage) and apoptosis is still favored towards the former in the colon of these subjects. The modified pathways belonging to the cellular processes of cell adhesion and cytoskeleton remodeling all appear to be interrelated since they share a large number of significant genes. The overall theoretical effect that can be deduced from these pathways points towards promotion of stress fiber formation (Suppl. Table 4 and Suppl. Figs. 3D-F, $\mathrm{H}$ and I). Stress fibers are formed in response to genotoxic stressors through activation of the small GTPase RhoA, and play a role in delaying cell death which is in agreement with the anti-apoptotic response found in the apoptosis pathway (Guerra et al., 2008). The expression of RhoA was indeed increased in this pathway as fecal water genotoxicity increased (Suppl. Table 4). Stress fiber formation is also supported by modifications in the Slit-Robo pathway, which is involved in cytoskeleton reorganization and displays a large degree of overlap with the cytoskeleton remodeling and cell adhesion pathways (Suppl. Fig. 3K).

One of the most interesting pathways found to be related to fecal water genotoxicity is the strongly modified WNT signaling pathway which is involved in epithelial proliferation and differentiation. Aberrant activation of WNT signaling represents a major oncogenic process in the development of many epithelial cancers, including CRC (Bienz and Clevers, 2000; Fearon and Vogelstein, 1990; Segditsas and Tomlinson, 2006). Activation of WNT signaling results in $\beta$-catenin accumulation which subsequently forms a complex with the transcription factor TCF/LEF resulting in the activation of oncogenic target genes. Our results indicate that expression of the TCF/LEF transcription factor in this pathway increases with the level of fecal water genotoxicity (Suppl. Table 4 and Suppl. Fig. 3L). This constitutes a carcinogenic risk and could be an important discovery in explaining the red meat intake-associated cancer risk in humans. Moreover, since the WNT signaling pathway is also targeted by p53 (Lee et al., 2010), our observation of pathways involving p53 regulation suggests a close link between fecal water genotoxicity, DNA damage control by $\mathrm{p} 53$, and WNT signaling. We have also previously found modifications in WNT signaling in Caco-2 cells following exposure to an oxidative environment (Briede et al., 2010), suggesting that oxidative mechanisms may be responsible for the effects seen here. Interestingly, Brookes et al. (2008) have demonstrated that iron increases WNT signaling. Since iron plays an essential role in mediating the oxidative genotoxicity associated with heme exposure, this is another indication that heme protein plays a role in the effects observed here. In this line, modifications in genes controlling epithelial proliferation and differentiation have been discovered in rats following an increase in dietary heme intake (van der Meer-van Kraaij et al., 2005). It could be hypothesized that the gene expression response associated with red meat intake-induced fecal water genotoxicity is attributable to the heme content of red meat and this would be a worthwhile topic for future research. The transcriptomic modifications in the WNT pathway in particular are interesting targets for validation in novel studies focusing on the relation between red meat intake or oxidative stress and the development of CRC.

Another interesting discovery is the Sin 3 and NuRD transcription regulation pathway. Sin3 and NuRD are nucleosome remodeling and histone deacetylase complexes that control transcriptional repression (Ahringer, 2000; Feng and Zhang, 2003) and several genes that form part of these complexes, including histone deacetylase 2 , were positively correlated with fecal water genotoxicity levels (Suppl. Table 4 and Suppl. Fig. 3S). NuRD complex-induced gene silencing has also been demonstrated in colon cancer cells (Zhu et al., 2004; Zuo et al., 2009). These modifications point towards an epigenetic mechanism by which red meat could influence important molecular pathways.

The remaining pathways are suggestive of modifications in carbohydrate and cholesterol metabolism, but it is not clear what their relevance could be in relation to fecal water genotoxicity.

In summary, we observed a red meat intake-induced increase in fecal water genotoxicity which was not related to fecal NOC content nor influenced by inflammation in the colon. We propose that heme protein is a likely candidate for this increase, especially since fecal water-induced oxidative damage was higher following the intervention. Furthermore, we have identified a large number of pathway modifications related to red meat intake-induced fecal water genotoxicity some of which could contribute to carcinogenic transformations in the human colon. The gene expression changes identified in this study corroborate the genotoxic potential of a diet high in red meat and point towards a possible risk for CRC development in humans.

\section{Conflict of Interest}

The authors declare no conflict of interest.

\section{Funding}

This study was internally funded by Maastricht University.

\section{Acknowledgments}

The authors would like to acknowledge Mr. Herman Vermaas for his advice on the meat intervention. Furthermore, we would like to recognize the efforts of the endoscopy department staff at the Orbis Medical Center and the Maastricht University Medical Center and thank the study subjects for their participation. The 
authors also wish to acknowledge Liliane Jimenez-Van Hoorn, Tammy Oth, and Kevin van Tilburg for their technical assistance.

\section{Appendix A. Supplementary data}

Supplementary data associated with this article can be found, in the online version, at doi:10.1016/j.fct.2011.10.038.

\section{References}

Ahringer, J., 2000. NuRD and SIN3 histone deacetylase complexes in development. Trends Genet. 16, 351-356.

Autrup, H., Harris, C.C., Trump, B.F., Jeffrey, A.M., 1978. Metabolism of benzo(a)pyrene and identification of the major benzo(a)pyrene-DNA adducts in cultured human colon. Cancer Res. 38, 3689-3696.

Balder, H.F., Vogel, J., Jansen, M.C., Weijenberg, M.P., van den Brandt, P.A., Westenbrink, S., van der Meer, R., Goldbohm, R.A., 2006. Heme and chlorophyll intake and risk of colorectal cancer in the Netherlands cohort study. Cancer Epidemiol. Biomarkers Prev. 15, 717-725.

Bienz, M., Clevers, H., 2000. Linking colorectal cancer to Wnt signaling. Cell 103, 311-320.

Bingham, S.A., Hughes, R., Cross, A.J., 2002. Effect of white versus red meat on endogenous $\mathrm{N}$-nitrosation in the human colon and further evidence of a dose response. J. Nutr. 132, 3522S-3525S

Bingham, S.A., Pignatelli, B., Pollock, J.R., Ellul, A., Malaveille, C., Gross, G., Runswick, S., Cummings, J.H., O'Neill, I.K., 1996. Does increased endogenous formation of $\mathrm{N}$-nitroso compounds in the human colon explain the association between red meat and colon cancer? Carcinogenesis 17, 515-523.

Bjeldanes, L.F., Morris, M.M., Felton, J.S., Healy, S., Stuermer, D., Berry, P., Timourian, H., Hatch, F.T., 1982. Mutagens from the cooking of food. II. Survey by Ames Salmonella test of mutagen formation in the major protein-rich foods of the American diet. Food Chem. Toxicol. 20, 357-363.

Bolos, V., Grego-Bessa, J., de la Pompa, J.L., 2007. Notch signaling in development and cancer. Endocr. Rev. 28, 339-363.

Briede, J.J., van Delft, J.M., de Kok, T.M., van Herwijnen, M.H., Maas, L.M., Gottschalk, R.W., Kleinjans, J.C., 2010. Global gene expression analysis reveals differences in cellular responses to hydroxyl- and superoxide anion radical-induced oxidative stress in caco-2 cells. Toxicol. Sci. 114, 193-203.

Brookes, M.J., Boult, J., Roberts, K., Cooper, B.T., Hotchin, N.A., Matthews, G., Iqbal, T., Tselepis, C., 2008. A role for iron in Wnt signalling. Oncogene 27, 966-975.

Cross, A.J., Ferrucci, L.M., Risch, A., Graubard, B.I., Ward, M.H., Park, Y., Hollenbeck, A.R., Schatzkin, A., Sinha, R., 2010. A large prospective study of meat consumption and colorectal cancer risk: an investigation of potential mechanisms underlying this association. Cancer Res. 70, 2406-2414.

Cross, A.J., Greetham, H.L., Pollock, J.R., Rowland, I.R., Bingham, S.A., 2006. Variability in fecal water genotoxicity, determined using the Comet assay, is independent of endogenous $N$-nitroso compound formation attributed to red meat consumption. Environ. Mol. Mutagen. 47, 179-184.

Cross, A.J., Pollock, J.R., Bingham, S.A., 2003. Haem, not protein or inorganic iron, is responsible for endogenous intestinal $\mathrm{N}$-nitrosation arising from red meat. Cancer Res. 63, 2358-2360.

Cross, A.J., Sinha, R., 2004. Meat-related mutagens/carcinogens in the etiology of colorectal cancer. Environ. Mol. Mutagen. 44, 44-55.

de Kok, T.M., Engels, L.G., Moonen, E.J., Kleinjans, J.C., 2005. Inflammatory bowel disease stimulates formation of carcinogenic $N$-nitroso compounds. Gut 54, 731.

Fearon, E.R., Vogelstein, B., 1990. A genetic model for colorectal tumorigenesis. Cell 61, 759-767.

Felton, J.S., Fultz, E., Dolbeare, F.A., Knize, M.G., 1994. Effect of microwave pretreatment on heterocyclic aromatic amine mutagens/carcinogens in fried beef patties. Food Chem. Toxicol. 32, 897-903.

Feng, Q., Zhang, Y., 2003. The NuRD complex: linking histone modification to nucleosome remodeling. Curr. Top. Microbiol. Immunol. 274, 269-290.

Glei, M., Klenow, S., Sauer, J., Wegewitz, U., Richter, K., Pool-Zobel, B.L., 2006. Hemoglobin and hemin induce DNA damage in human colon tumor cells HT29 clone 19A and in primary human colonocytes. Mutat. Res. 594, 162-171.

Guerra, L., Carr, H.S., Richter-Dahlfors, A., Masucci, M.G., Thelestam, M., Frost, J.A., Frisan, T., 2008. A bacterial cytotoxin identifies the RhoA exchange factor Net1 as a key effector in the response to DNA damage. PLoS One 3, e2254.

Haorah, J., Zhou, L., Wang, X., Xu, G., Mirvish, S.S., 2001. Determination of total Nnitroso compounds and their precursors in frankfurters, fresh meat, dried salted fish, sauces, tobacco, and tobacco smoke particulates. J. Agric. Food Chem. 49, 6068-6078.

Hebels, D.G., Briede, J.J., Khampang, R., Kleinjans, J.C., de Kok, T.M., 2010. Radical mechanisms in nitrosamine- and nitrosamide-induced whole-genome gene expression modulations in Caco-2 cells. Toxicol. Sci. 116, 194-205.

Hebels, D.G., Jennen, D.G., Kleinjans, J.C., de Kok, T.M., 2009. Molecular signatures of $\mathrm{N}$-nitroso compounds in Caco-2 cells: implications for colon carcinogenesis. Toxicol. Sci. 108, 290-300

Hebels, D.G., Sveje, K.M., de Kok, M.C., van Herwijnen, M.H., Kuhnle, G.G., Engels, L.G., Vleugels-Simon, C.B., Mares, W.G., Pierik, M., Masclee, A.A., Kleinjans, J.C., de Kok, T.M., 2011. N-nitroso compound exposure-associated transcriptomic profiles are indicative of an increased risk for colorectal cancer. Cancer Lett. 309, $1-10$.

Hughes, R., Cross, A.J., Pollock, J.R., Bingham, S., 2001. Dose-dependent effect of dietary meat on endogenous colonic $N$-nitrosation. Carcinogenesis 22, 199-202.

Jägerstad, M., Skog, K., 2005. Genotoxicity of heat-processed foods. Mutat. Res. 574 156-172.

Klinder, A., Forster, A., Caderni, G., Femia, A.P., Pool-Zobel, B.L., 2004. Fecal water genotoxicity is predictive of tumor-preventive activities by inulin-like oligofructoses, probiotics (Lactobacillus rhamnosus and Bifidobacterium lactis) and their synbiotic combination. Nutr. Cancer 49, 144-155.

Knize, M.G., Felton, J.S., 2005. Formation and human risk of carcinogenic heterocyclic amines formed from natural precursors in meat. Nutr. Rev. 63, 158-165.

Kuhnle, G.G., Bingham, S.A., 2007. Dietary meat, endogenous nitrosation and colorectal cancer. Biochem. Soc. Trans. 35, 1355-1357.

Kuhnle, G.G., Story, G.W., Reda, T., Mani, A.R., Moore, K.P., Lunn, J.C., Bingham, S.A., 2007. Diet-induced endogenous formation of nitroso compounds in the GI tract. Free Radic. Biol. Med. 43, 1040-1047.

Lakin, N.D., Jackson, S.P., 1999. Regulation of p53 in response to DNA damage. Oncogene 18, 7644-7655.

Lee, D.H., Anderson, K.E., Harnack, L.J., Folsom, A.R., Jacobs Jr., D.R., 2004. Heme iron, zinc, alcohol consumption, and colon cancer: Iowa Women's Health Study. J. Natl. Cancer Inst. 96, 403-407.

Lee, K.H., Li, M., Michalowski, A.M., Zhang, X., Liao, H., Chen, L., Xu, Y., Wu, X. Huang, J., 2010. A genomewide study identifies the Wnt signaling pathway as a major target of p53 in murine embryonic stem cells. Proc. Natl. Acad. Sci. USA 107, 69-74.

Levine, A.J., 1997. P53, the cellular gatekeeper for growth and division. Cell 88, 323 331.

Lijinsky, W., 1992. Chemistry and biology of $N$-nitroso compounds. Cambridge Univ. Press, Cambridge, UK.

Mirvish, S.S., Haorah, J., Zhou, L., Hartman, M., Morris, C.R., Clapper, M.L., 2003. Nnitroso compounds in the gastrointestinal tract of rats and in the feces of mice with induced colitis or fed hot dogs or beef. Carcinogenesis 24, 595-603.

Moonen, H., Engels, L., Kleinjans, J., Kok, T., 2005. The CYP1A2-164A->C polymorphism $(\mathrm{CYP} 1 \mathrm{~A} 2 * 1 \mathrm{~F})$ is associated with the risk for colorectal adenomas in humans. Cancer Lett. 229, 25-31.

Netherlands Nutrition Centre [Stichting Voedingscentrum Nederland], 2010 Nutrient information.

Ozel, M.Z., Gogus, F., Yagci, S., Hamilton, J.F., Lewis, A.C., 2010. Determination of volatile nitrosamines in various meat products using comprehensive gas chromatographynitrogen chemiluminescence detection. Food Chem. Toxicol. 48, 3268-3273.

Pearson, J.R., Gill, C.I., Rowland, I.R., 2009. Diet, fecal water, and colon cancer development of a biomarker. Nutr. Rev. 67, 509-526.

Pflaum, M., Will, O., Epe, B., 1997. Determination of steady-state levels of oxidative DNA base modifications in mammalian cells by means of repair endonucleases. Carcinogenesis 18, 2225-2231.

Rao, T.K., Lijinsky, W., Epler, J.L., 1984. Genotoxicology of $N$-nitroso compounds. In: de Serres, F.J. (Ed.), Topics in Chemical Mutagenesis. Plenum Press, New York.

Salmon, C.P., Knize, M.G., Felton, J.S., Zhao, B., Seow, A., 2006. Heterocyclic aromatic amines in domestically prepared chicken and fish from Singapore Chinese households. Food Chem. Toxicol. 44, 484-492.

Segditsas, S., Tomlinson, I., 2006. Colorectal cancer and genetic alterations in the Wnt pathway. Oncogene 25, 7531-7537.

Sesink, A.L., Termont, D.S., Kleibeuker, J.H., Van der Meer, R., 1999. Red meat and colon cancer: the cytotoxic and hyperproliferative effects of dietary heme. Cancer Res. 59, 5704-5709.

Shi, L., Reid, L.H., Jones, W.D., Shippy, R., Warrington, J.A., Baker, S.C., Collins, P.J., de Longueville, F., Kawasaki, E.S., Lee, K.Y., Luo, Y., Sun, Y.A., Willey, J.C., Setterquist R.A., Fischer, G.M., Tong, W., Dragan, Y.P., Dix, D.J., Frueh, F.W., Goodsaid, F.M., Herman, D., Jensen, R.V., Johnson, C.D., Lobenhofer, E.K., Puri, R.K., Schrf, U., Thierry-Mieg, J., Wang, C., Wilson, M., Wolber, P.K., Zhang, L., Amur, S., Bao, W., Barbacioru, C.C., Lucas, A.B., Bertholet, V., Boysen, C., Bromley, B., Brown, D., Brunner, A., Canales, R., Cao, X.M., Cebula, T.A., Chen, J.J., Cheng, J., Chu, T.M., Chudin, E., Corson, J., Corton, J.C., Croner, L.J., Davies, C., Davison, T.S., Delenstarr, G., Deng, X., Dorris, D., Eklund, A.C., Fan, X.H., Fang, H., Fulmer-Smentek, S. Fuscoe, J.C., Gallagher, K., Ge, W., Guo, L., Guo, X., Hager, J., Haje, P.K., Han, J., Han, T., Harbottle, H.C., Harris, S.C., Hatchwell, E., Hauser, C.A., Hester, S., Hong, H., Hurban, P., Jackson, S.A., Ji, H., Knight, C.R., Kuo, W.P., LeClerc, J.E., Levy, S., Li, Q.Z., Liu, C., Liu, Y., Lombardi, M.J., Ma, Y., Magnuson, S.R., Maqsodi, B., McDaniel T., Mei, N., Myklebost, O., Ning, B., Novoradovskaya, N., Orr, M.S., Osborn, T.W. Papallo, A., Patterson, T.A., Perkins, R.G., Peters, E.H., Peterson, R., Philips, K.L. Pine, P.S., Pusztai, L., Qian, F., Ren, H., Rosen, M., Rosenzweig, B.A., Samaha, R.R. Schena, M., Schroth, G.P., Shchegrova, S., Smith, D.D., Staedtler, F., Su, Z., Sun, H., Szallasi, Z., Tezak, Z., Thierry-Mieg, D., Thompson, K.L., Tikhonova, I., Turpaz, Y. Vallanat, B., Van, C., Walker, S.J., Wang, S.J., Wang, Y., Wolfinger, R., Wong, A., Wu, J., Xiao, C., Xie, Q., Xu, J., Yang, W., Zhang, L., Zhong, S., Zong, Y., Slikker Jr., W., 2006. The MicroArray Quality Control (MAQC) project shows inter- and intraplatform reproducibility of gene expression measurements. Nat. Biotechnol. 24, 1151-1161.

Singh, N.P., McCoy, M.T., Tice, R.R., Schneider, E.L., 1988. A simple technique for quantitation of low levels of DNA damage in individual cells. Exp. Cell Res. 175, 184-191.

Tappel, A., 2007. Heme of consumed red meat can act as a catalyst of oxidative damage and could initiate colon, breast and prostate cancers, heart disease and other diseases. Med. Hypotheses 68, 562-564. 
van der Meer-van Kraaij, C., Kramer, E., Jonker-Termont, D., Katan, M.B., van der Meer, R., Keijer, J., 2005. Differential gene expression in rat colon by dietary heme and calcium. Carcinogenesis 26, 73-79.

Vermeer, I.T., Moonen, E.J., Dallinga, J.W., Kleinjans, J.C., van Maanen, J.M., 1999. Effect of ascorbic acid and green tea on endogenous formation of $\mathrm{N}$ nitrosodimethylamine and $\mathrm{N}$-nitrosopiperidine in humans. Mutat. Res. 428, 353-361.

Wakabayashi, K., Nagao, M., Esumi, H., Sugimura, T., 1992. Food-derived mutagens and carcinogens. Cancer Res. 52, 2092s-2098s.
Watson, I.R., Irwin, M.S., 2006. Ubiquitin and ubiquitin-like modifications of the p53 family. Neoplasia 8, 655-666.

Zhu, P., Martin, E., Mengwasser, J., Schlag, P., Janssen, K.P., Gottlicher, M., 2004. Induction of HDAC2 expression upon loss of APC in colorectal tumorigenesis. Cancer Cell 5, 455-463.

Zuo, X., Morris, J.S., Broaddus, R., Shureiqi, I., 2009. 15-LOX-1 transcription suppression through the NuRD complex in colon cancer cells. Oncogene 28, 1496-1505. 